\title{
Phacelia (Phacelia tanacetifolia Benth.) affects soil structure differently depending on soil texture
}

\author{
A. Bacq-Labreuil • J. Crawford • S. J. Mooney • \\ A. L. Neal • K. Ritz
}

Received: 23 November 2018 / Accepted: 16 April 2019/Published online: 11 June 2019

(C) The Author(s) 2019

\begin{abstract}
Aims We studied the effects of Phacelia tanacetifolia, increasingly used as a cover-crop species in arable agricultural systems, upon soil structural properties in the context of two contrasting soil textures. We hypothesised there would be differential effects of the plants upon soil structure contingent on the texture.

Methods A sandy-loam and a clay soil were destructured by passing through $2 \mathrm{~mm}$ sieves, and planted with Phacelia in a replicated pot experiment, with associated unplanted controls. X-ray Computed Tomography was used to visualise and quantify the soil pore networks in 3D.

Results For the sandy-loam soil, there was no impact of plants upon aggregate size distribution porosity, pore connectivity, and pore surface density decreased in the presence of plants, whereas for the clay, there was a significant increase of aggregates $<1000 \mu \mathrm{m}$, the porosity was constant, the pore-connectivity decreased, and surface density increased in the presence of plants.

Conclusions Plants can impact the structural genesis of soil depending on its inherent textural characteristics,
\end{abstract}

Responsible Editor: W Richard Whalley.

A. Bacq-Labreuil $(\bowtie) \cdot$ S. J. Mooney $\cdot$ K. Ritz

Division of Agriculture \& Environmental Sciences, School of

Biosciences, University of Nottingham, Sutton Bonington

Campus, Leicestershire LE12 5RD, UK

e-mail: aurelie.bacqlabreuil@gmail.com

J. Crawford · A. L. Neal

Department of Sustainable Agriculture Science, Rothamsted

Research, West Common, Harpenden AL5 2JQ, UK leading to a differential development of pore architecture in different contexts. These results have implications both from an ecological perspective and in terms of the prescription of plants to remediate or condition soil structure in managed systems.

Keywords Cover crop · Phacelia · Soil pore connectivity $\cdot$ Soil porosity $\cdot$ X-ray computed tomography $\cdot 3 \mathrm{D}$ image analysis

\section{Introduction}

In terrestrial systems, soil is the fundamental base which supports vegetation growth (van Breemen 1993), but plants also affect the nature of their belowground habitat both directly and indirectly. In agricultural systems, the use of cover crops is increasing (Storr et al. 2019) in order to increase the sequestration of carbon (Reicosky and Forcella 1998; Scott et al. 2017), soil macroporosity (Abdollahi et al. 2014; Bodner et al. 2014; Burr-Hersey et al. 2017; Cercioglu et al. 2018) and decrease soil erosion (Reicosky and Forcella 1998; Storr et al. 2019). Furthermore, cover crops have an impact on the biota of the soil, increasing microbial diversity and richness (Patkowska and Konopiński 2013; Fernandez et al. 2016) and the abundance of saprophytic and mycorrhizal fungi (Six et al. 2006; Duchene et al. 2017; Finney et al. 2017). In a restored grassland, roots and fungi increased the proportion of carbon sequestered in aggregate (Scott et al. 2017), however, there was no measurement of the pore 
network, and the characterisation of the soil structure was via aggregate size. Bodner et al. (2014) showed that cover crops with different root architectures induced different porosity and pore size distributions determined via water infiltration (i.e. a destructive method). The physical structure of the soil was not visualised. X-ray Computed Tomography is a non-destructive method which image the soil structure as well as the roots (Zhou et al. 2016; Cercioglu et al. 2018; Rabot et al. 2018; Schlüter et al. 2018). A recent study revealed contrasting responses between species in their root morphology to changes in bulk density (Burr-Hersey et al. 2017), but presented little information on associated soil structure. Cover crops and biofuel crops can improve soil pore characteristics via increasing the macro-porosity and decreasing soil bulk density (Cercioglu et al. 2018).

Soil structure is classically defined as the arrangement of soil particles and organic materials (Tisdall and Oades 1982), typically creating a dynamic and heterogeneous pore network within the soil matrix (Dexter 1988). The nature of this pore network is to a large extent underpinned by soil texture, but it can also be affected by other factors such as the actions of living organisms, wet:dry and freeze:thaw cycles, etc. (Ritz and Young 2011). A recent study revealed tomato root architecture was markedly different for plants after 8 days of growth dependant on soil texture: plants developed a thick tap root in sandy loam soil but grew thinner roots with more laterals in clay soil (Helliwell et al. 2017). Furthermore, the porosity of the rhizosphere of the sandy loam soil was decreased whereas for the clay loam soil it was increased. Thus, the root growth strategies of plants are influenced by the surrounded environment. In non-cohesive and coarser soil, root systems generally develop to greater depth and are thicker than roots growing in a cohesive, finer textured soil (Hacke et al. 2000; Jackson et al. 2000; Li et al. 2005). Non-cohesive and coarser soil dries at greater rates in the upper layer, therefore the root systems must grow deeper in order to access water (Jackson et al. 2000). The influence of plants on soil structural dynamics is also dependant on soil texture: in a silty-clay soil the presence of plant can increase the porosity and pore connectivity compared to a sandy soil where the presence of plants can decrease the porosity and poreconnectivity (Bacq-Labreuil et al. 2018). However, the effects of soil texture upon the impact of plants upon soil structural dynamics is not well understood. Hydraulic properties in finer textured soils are considerably different due to the enhanced water holding in finer pores (Saxton et al. 1986). Plant roots modify the aggregation of soil particles, generally acting to generate and stabilise aggregates (Tisdall and Oades 1982). This occurs by processes of enmeshment of soil particles and excretion of mucilage and other extra-cellular polymeric substances which adhere constituents together (Bronick and Lal 2005; Erktan et al. 2018; Gould et al. 2016). Indirect mechanisms are mediated by interactions with soil biota also serve to drive aggregation processes such as excretion of extracellular substances (Haynes and Beare 1997; Rillig et al. 2002; Ritz and Young 2011). Root mucilage stabilises aggregates by increasing cohesion and decreasing wetting rates of aggregates (Czarnes et al. 2000). The inherent diversity of plant species means that the soil is frequently exposed to an increase in the diversity of root architecture within the matrix (e.g. tap, fibrous, fine roots), an increase in the quality and quantity of carbon inputs, and considerable differentiation in the microbial communities associated with the root systems (Haynes and Beare 1997; Chan and Heenan 1999; Rillig et al. 2002; Gould et al. 2016).

The aim of this study was to establish the effect of soil texture and plant growth on early stage soil structural genesis. We grew Phacelia tanacetifolia, a herbaceous plant commonly used as a cover crop in arable rotations and apocryphally thought to be particularly effective in conditioning soil structure, in a sandy loam and clay soil, along with unplanted control treatments. We hypothesised that (i) the plant roots have a contrasting effect on soil structure (via the modification of aggregate distribution and pore network) depending on the soil texture; and (ii) the presence of a plant increases the porosity, pore-connectivity, and diversity of pore sizes.

\section{Materials and methods}

Preparation of soil cores

Soil from the Newport series, a sandy loam (clay: $9.5 \%$, silt: $26.1 \%$, sand: $65.3 \%$; organic matter $2.9 \%$, pH 6.3 ; FAO Brown Soil) and soil from the Worcester series, a clay (clay: $43.3 \%$, silt: $28.4 \%$, sand: $28.3 \%$; pH 6.5 , organic matter $5.2 \%$, pH 6.5; FAO Argillic Pelosol) were collected from the top $50 \mathrm{~cm}$ of arable fields situated in Bunny, Nottinghamshire, UK (52.52 ${ }^{\circ} \mathrm{N}$, 
$\left.1.07^{\circ} \mathrm{W}\right)$. After collection, the soils were spread and left to air-dry over two days before being thoroughly mixed and broken down by passing through a $2-\mathrm{mm}$ mesh sieve. Columns comprised of polypropylene tubes (170 $\mathrm{mm}$ height $\times 68 \mathrm{~mm}$ diameter) with a $0.1 \mathrm{~mm}$ mesh affixed to the base were packed with soil to a bulk density of $1.2 \mathrm{~g} \mathrm{~cm}^{-3}$. Columns were placed on a tension table for saturation for $24 \mathrm{~h}$ and then equilibration for 3 days at $-3 \mathrm{kPa}$ prior to seed sowing which is equivalent to a moisture of $30 \%( \pm 2 \%)$ for the clay and $20 \%( \pm$ $1 \%$ ) for the sandy loam. Pre-germinated seeds of Phacelia tanacetifolia Benth. cv. "Angelia" were planted in the soil surface and adjusted to provide one emergent plant per column. Four planted and four unplanted replicates of each soil type were established and arranged in a randomised block design in a growth chamber providing $16: 8 \mathrm{~h}$ light:dark cycle at $21^{\circ} \mathrm{C}: 50 \%$ humidity, $15{ }^{\circ} \mathrm{C}: 75 \%$ humidity respectively and the moisture content was kept constant by maintaining the plants on a tension table at $-3 \mathrm{kPa}$. Plants were grown for 6 weeks since at this age they were fully pot-bound.

X-ray computed tomography $(\mathrm{CT})$

All columns were X-ray CT scanned prior to sowing seeds, and at 2, 4 and 6 weeks thereafter, using a Phoenix $\mathrm{v} \mid$ tome $\mid \mathrm{x}$ M scanner (GE Measurement and Control solution, Wunstorf, Germany) set at a voxel resolution of $40 \mu \mathrm{m}$, the voltage of $180 \mathrm{kV}$ with a current of $180 \mu \mathrm{A}$. A total of 2160 projection images were collected for each scan at an exposure time of $250 \mathrm{~ms}$ period using an averaging of 3 images and skip of 1 , resulting in a total scan time of $90 \mathrm{~min}$. The scanning time was chosen to optimise the image processing with greater quality of image. Scans occurred over 4 days with treatments randomly allocated over this period but consistent between the three occasions.

All scanned images were reconstructed using Phoenix datos $\mid \times 2$ rec reconstruction software. The scanned images were optimised to correct any sample movement during the scan and reduce noise using the beam hardening correction algorithm, set at 8 . Here, beam hardening was set at 8 , due to previous tests which gave the best image quality.

As a multi-scan routine was performed on the core samples, VG StudioMax ${ }^{\circledR} 2.2$ was used to merge the top, middle and bottom scans to obtain a single $3 \mathrm{D}$ volume for each complete core. Image sequences of $40 \times 40 \times 120 \mathrm{~mm}$ were extracted for image analysis.
Image analysis

Pre-processing of the image sequences was performed using Image J (Schneider et al. 2012). This step was used to crop the image sequence, apply a median filter (averaging 2 pixels), enhance brightness and contrast, and selected two threshold values manually. The threshold and the 3D calculation was implemented in QuantIm (Vogel et al. 2010), following a standard method detail in Bacq-Labreuil et al. (2018), described briefly here. The segmentation of the pore networks was realised in $3 \mathrm{D}$, and only included the pores and left out the root materials. The threshold was facilitated by the long scanning procedure which enhanced the image quality. The threshold used here is a 3D threshold using an neighbour-algorithm, i.e. the software requires 2 threshold values $\left(T_{1}<T_{2}\right)$ and compares every voxel greyscale value $\left(\mathrm{T}_{\mathrm{i}}\right)$ to this two values. If $\mathrm{T}_{\mathrm{i}}<\mathrm{T}_{1}, \mathrm{~T}_{\mathrm{i}}$ is attributed to the pore phase, if $T_{i}>T_{2}$, Ti is attributed to the solid phase and if $\mathrm{T}_{1}<\mathrm{T}_{\mathrm{i}}<\mathrm{T}_{2}$, Ti is attributed to the fuzzy regions. When all the voxels are attributed to each of the three phases, then the software compares the voxel from the fuzzy regions to their neighbours: if one of $T_{i}$ neighbour belongs to the pore space, then $T_{i}$ is attributed to the pore phase otherwise $T_{i}$ stays in the fuzzy region. This step is repeated until no changes can be made, all the voxel in the fuzzy region is attributed then to the solid phase. The quantification of the $3 \mathrm{D}$ pore network was performed by QuantIm (Vogel et al. 2010).

In summary, the following Minkowski function which characterised 3D pore network, were collected using QuantIm: porosity of the selected volume was the percentage of the pores greater than $40 \mu \mathrm{m}$, here referred as the porosity; pore size distribution, expressed here as a cumulative value, was the proportion of each size class in the volume; pore connectivity expressed by the Euler number, with a negative Euler number is associated with greater pore connectivity; pore surface density which is the pore-solid interface, a greater surface density suggests a larger roughness of the pore edges (Vogel et al. 2010).

Sampling and measurements

After 6 weeks, the columns were destructively harvested, and the soil air-dried. Aggregate size distribution was determined by passing $250 \mathrm{~g}$ of air-dried soil through a sieve series of 2000, 1000, 710, 500, 425, 

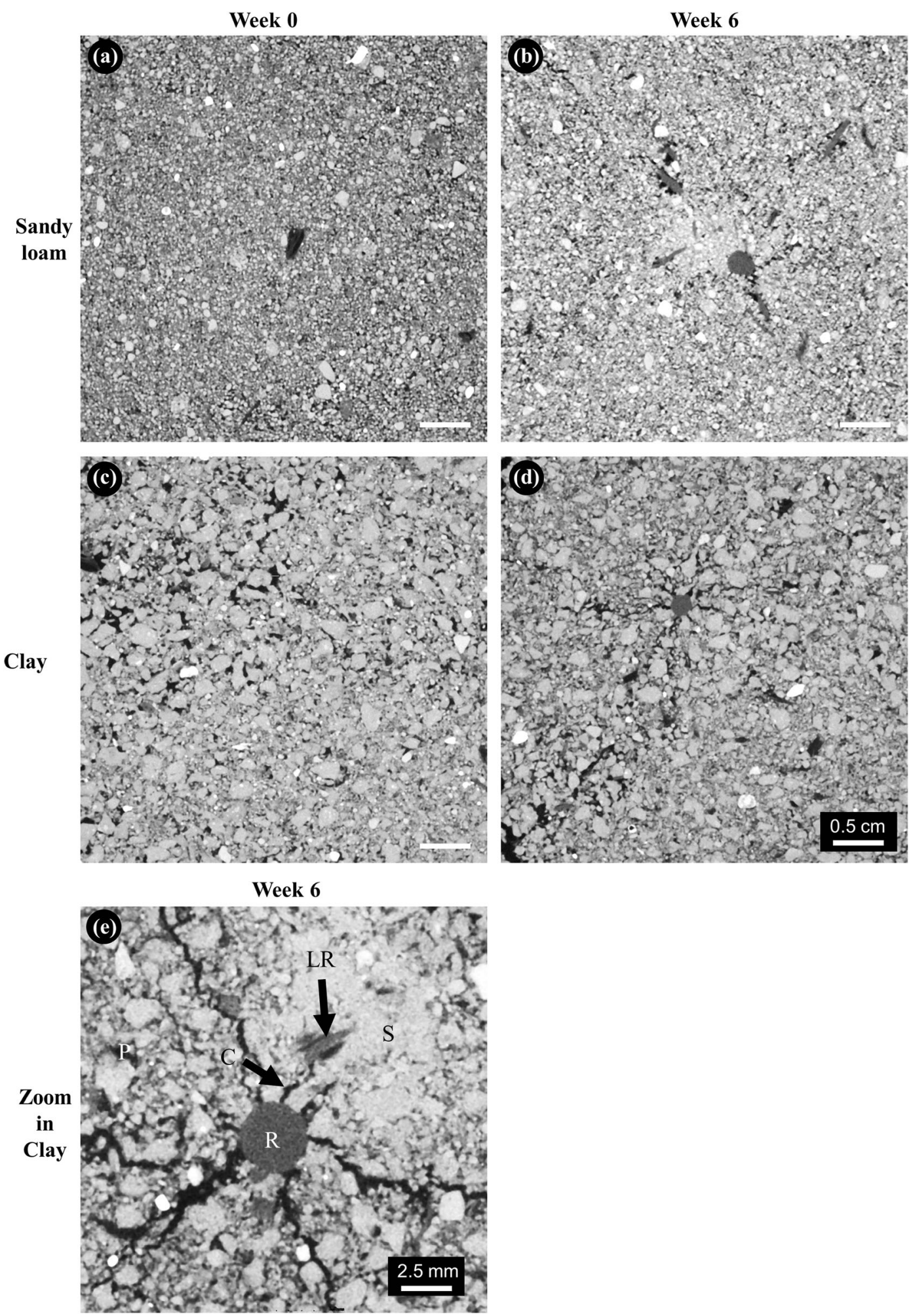

300,212 and $53 \mu \mathrm{m}$, via horizontal shaking for $3 \mathrm{~min}$ at 300 rotations $\mathrm{min}^{-1}$. The mass of aggregates retained on each sieve was determined and normalized to the total mass (Kézdi 1974). 
Fig. $12 \mathrm{D}$ X-ray attenuation images of soils $(40 \mu \mathrm{m}$ resolution; darker shades relate to lower attenuation; a sharpening algorithm has been passed over these images to increase contrast of features) from $(\mathbf{a}, \mathbf{c})$ unplanted at Week 0 and $(\mathbf{b}, \mathbf{d}, \mathbf{e})$ soil planted with phacelia after $6 . \mathbf{a}, \mathbf{b}$ sandy clay soils; (c, d) clay soils. e example of effect of lateral root (LR) growing from a primary root (R) through aggregate in the clay soil and resulting in crack (C), growing through the soil matrix $(\mathrm{S})$. P represents isolated pores

\section{Statistical analysis}

All statistical analyses were conducted using Genstat version 17.1 (VSN International Ltd., 2014). For aggregate size distribution, at Week 0 , a one-way analysis of variance (ANOVA) was performed to assess the difference in soil mass between size classes at Week 6, and for porosity a two-factor repeated-measures RM-ANOVA was used to assess the effects of plant status and either size class or time. A three-way RM-ANOVA was performed on all primary variables using a split-plot design with soil type, plant status and size classes of pores as factors.

\section{Results}

Both soils showed contrasting pore architectures (Fig. 1a, c). For the sandy soil, the pores were primarily compound-packing pores that were typically a similar small and well distributed through the soil profile (Fig. 1a). However, for the clay soil, pores were larger as a result of the destructuring (sieving) process, typically vugh-shaped and more heterogeneously distributed than the sand soil (Fig. 1c). In micromorphology terms a vugh is classified as an "irregular shaped pores" (Bullock and Murphy 1983). The growth of Phacelia after 6 weeks induced cracks in the soil surrounding the primary root, but were more apparent in the clay soil (Fig. 1b-e). Cracks were apparent, principally associated with primary roots within the soil profile (Fig. 1b, d) or with lateral roots growing through aggregates in the clay soil (Fig. 1e).

\section{Pore characteristics}

In the sandy loam soil, porosity decreased between Week 0 and Week 2 but not thereafter for the unplanted soil, whilst in planted soils there was a consistent decrease in porosity across Weeks $0-6$ (time x treatment interaction $P<0.05$; Fig. 2a). In the clay soil, porosity was less in planted treatments at Week 0 , similar at Week 2 and greater in planted soils at Week 6 than unplanted treatments (time $\mathrm{x}$ treatment interaction $P<0.001$; Fig. 2b).

Minkowski functions only showed significant changes with respect to pore diameters of $<0.3 \mathrm{~mm}$ for both sandy loam and clay soils (Figs. $3 \& 4$ ). For sandy loam there was a significant pore size diameter $\mathrm{x}$ treatment $\mathrm{x}$ time interaction term with respect to all pore size distribution, pore connectivity and pore surface density $(P \leq$ $0.01)$. Whilst this effect was statistically significant with respect to pore size distribution, in numerical terms the
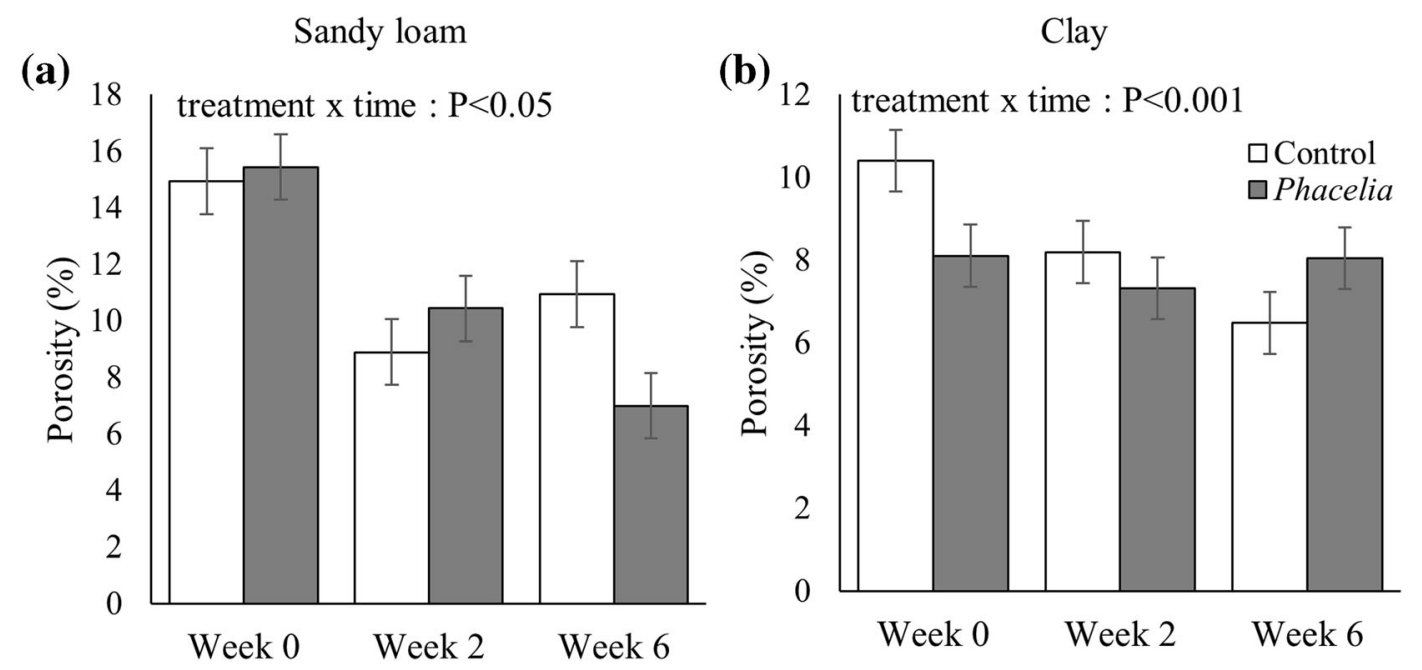

Fig. 2 Total soil porosity in unplanted and planted soils (spatial resolution $40 \mu \mathrm{m})$. a sandy loam soil; (b) clay soil. Bars denote means $(n=$ 4) expressed as the percentage of pores relative to the total volume, whiskers denote pooled standard errors 
WEEK 0

WEEK 2
WEEK 6

(c)

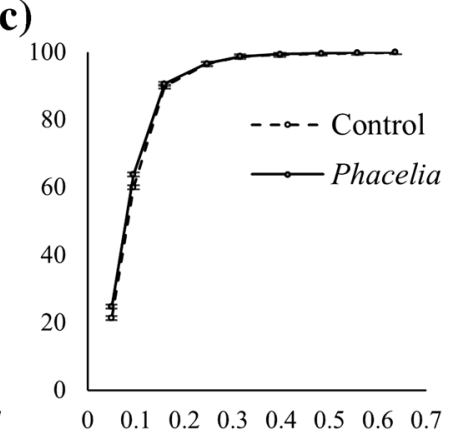

(a)

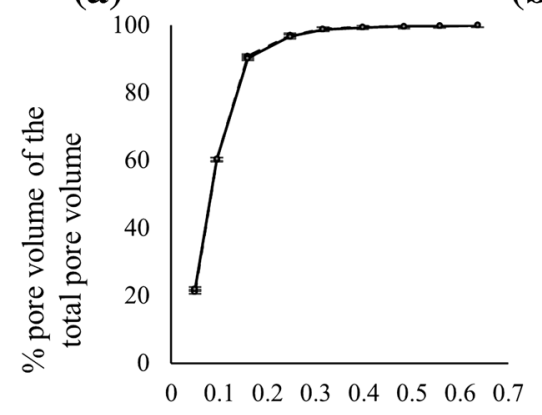

(b)

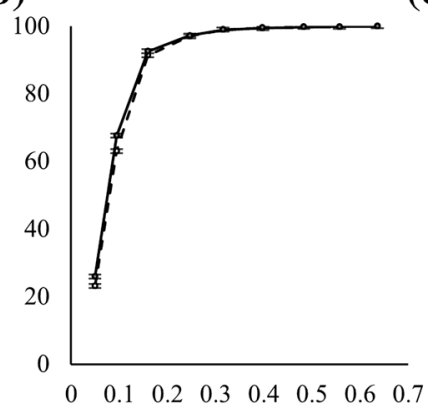

pore size diameter $\mathrm{x}$ treatment $\mathrm{x}$ time $: \mathrm{P}=0.01$

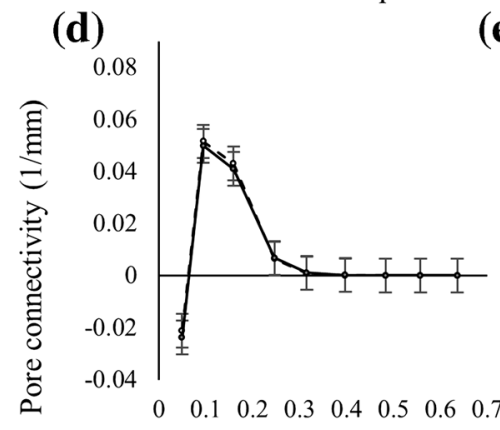

(e)

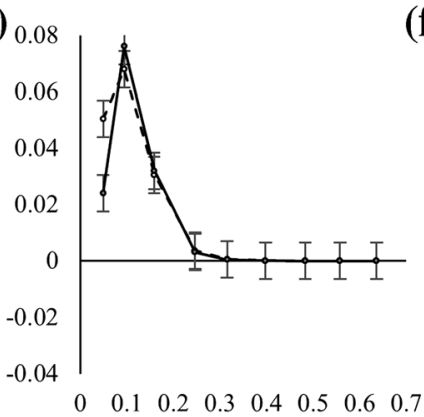

(f)

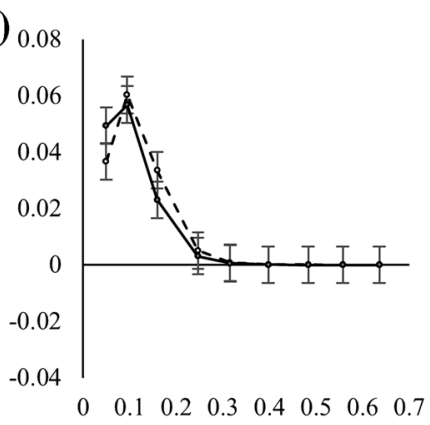
pore size diameter $\mathrm{x}$ treatment $\mathrm{x}$ time : $\mathrm{P}<0.001$

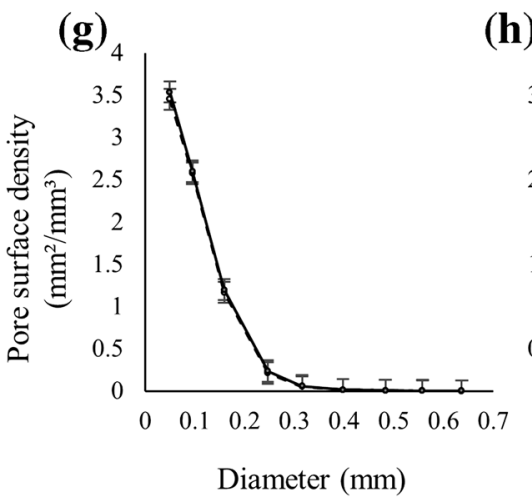

$(\mathbf{g})_{4}$

Fig. 3 Minkowski functions of sandy loam soils for the unplanted and planted soils at Week $0(\mathbf{a}, \mathbf{d}, \mathbf{g})$, Week $2(\mathbf{b}, \mathbf{e}, \mathbf{h})$ and Week 6 $(\mathbf{c}, \mathbf{f}, \mathbf{i})$ : $(\mathbf{a}-\mathbf{c})$ cumulative pore distribution of cores; $(\mathbf{d}-\mathbf{f})$

effects were minor, and barely discernible when plotted (Fig. 3 a-c). Approximately $90 \%$ of the pore sizes in all cases were $\leq 0.16 \mathrm{~mm}$ (Fig. $3 \mathrm{a}-\mathrm{c}$ ). The connectivity function of unplanted soils decreased significantly between Weeks 0 and 2, with only a modest increase by Week 6. However, on these occasions, plant effects on connectivity differed depending on pore size. At Week 2 , pores $<0.1 \mathrm{~mm}$ were more connected in planted soils but not above this size. By Week 6 this relationship changed such that pores $<0.1 \mathrm{~mm}$ were less connected, and those in the range $0.1-0.25 \mathrm{~mm}$ were more connected in planted soils. Pore surface density decreased for both unplanted and planted soils between Week 0 and Week 2 but with a greater magnitude for unplanted soils, and with this decline continuing in planted soils to Week 6 (Fig. 3 j-1).

For the clay soil, there was no significant three-way interaction term with respect to pore size distribution 
WEEK 0

WEEK 2

WEEK 6

(a)

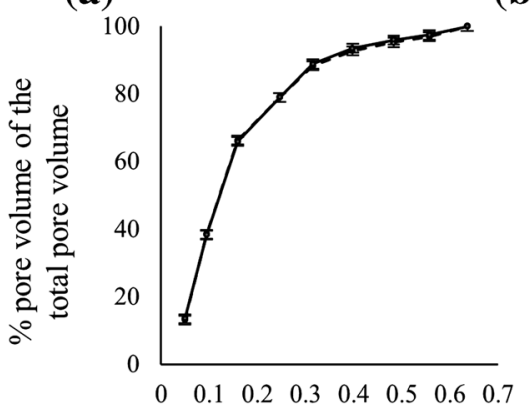

(b)

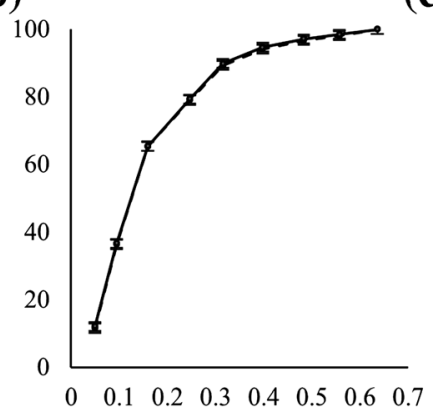

(c)

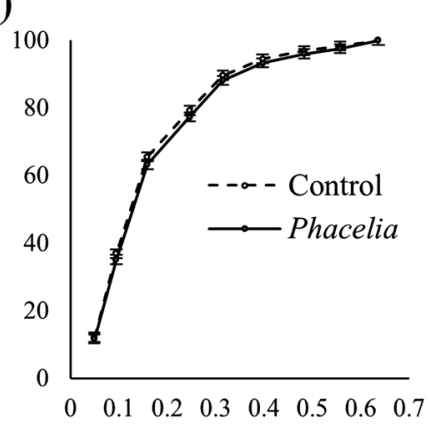

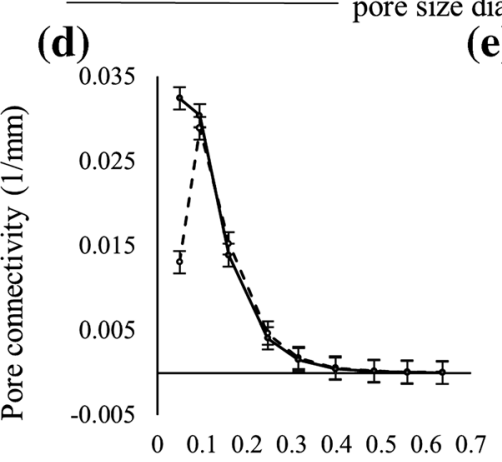

(e)

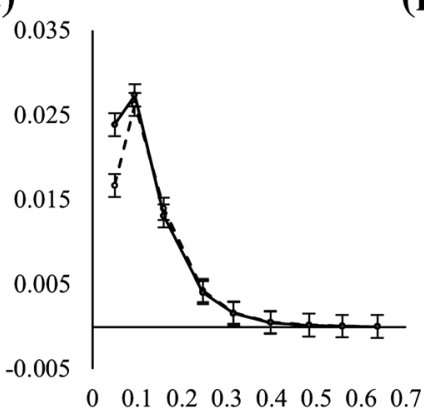

(f)

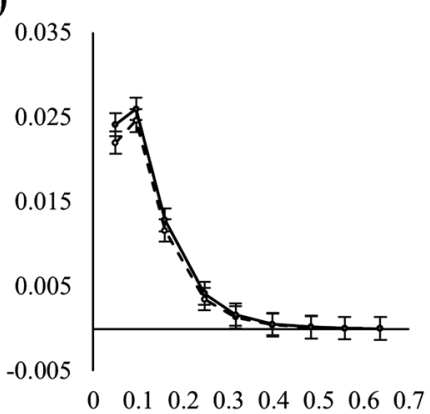

(g)

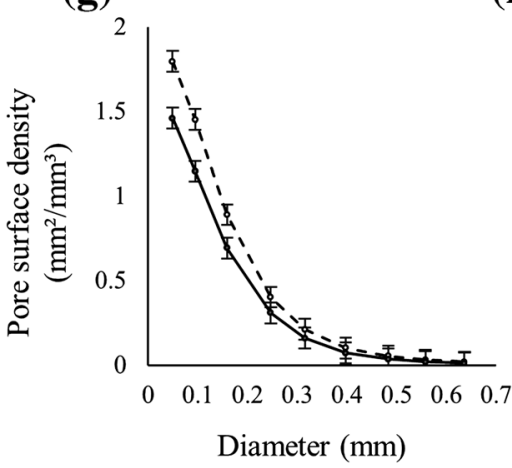

Fig. 4 Minkowski functions of clay soils for the unplanted and planted soils at Week 0 (a, d, g), Week 2 (b, e, h) and Week 6 (c, f, i): (a - c) cumulative pore distribution of cores; ( $\mathbf{d}$ - f) connectivity;

$(P>0.05$; Fig. 4 a-c), but there was for pore connectivity and pore surface density $(\mathrm{P}<0.001$; Fig. 4 d-1). Overall, approximately $80 \%$ of the pore sizes for both treatments were $\leq 0.25 \mathrm{~mm}$ (Fig. 3 a-c). At Week 0 , the pore connectivity of the unplanted soils was substantially greater than the planted soils for pores in the 0.05$0.1 \mathrm{~mm}$ size range (Fig. $4 \mathrm{~d}$ ). Over the subsequent 6 weeks, pore connectivity in planted and unplanted soils converged to parity (approximately $0.23 \mathrm{~mm}^{-1}$; Fig. 4 d-f), leading to a significant interaction. Pore surface density of unplanted soils was greater than planted soils by up to $0.3 \mathrm{~mm}$ at Week 0 . By Week 2, pore surface density functions had decreased and converged for both treatments, and by Week 6 was significantly smaller for pores $<0.2 \mathrm{~mm}$ in unplanted soils (Fig. 4 j-1). (i)

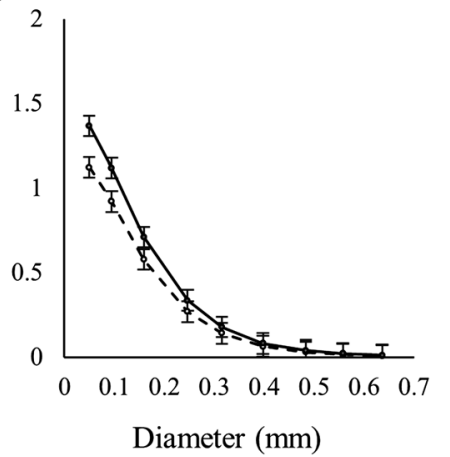

(g - i) surface density. Points denote means $(n=4)$, whiskers denote pooled standard errors 
Week 0

(a)

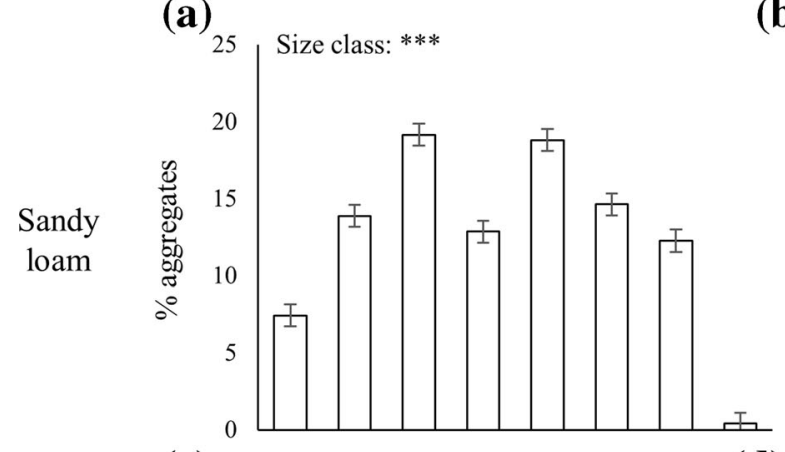

Week 6

(b)

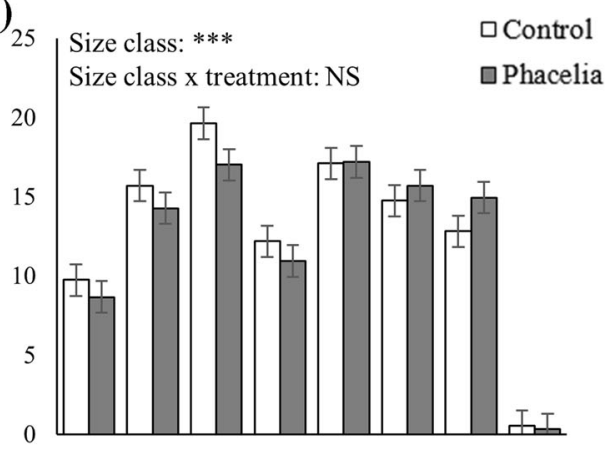

(c)

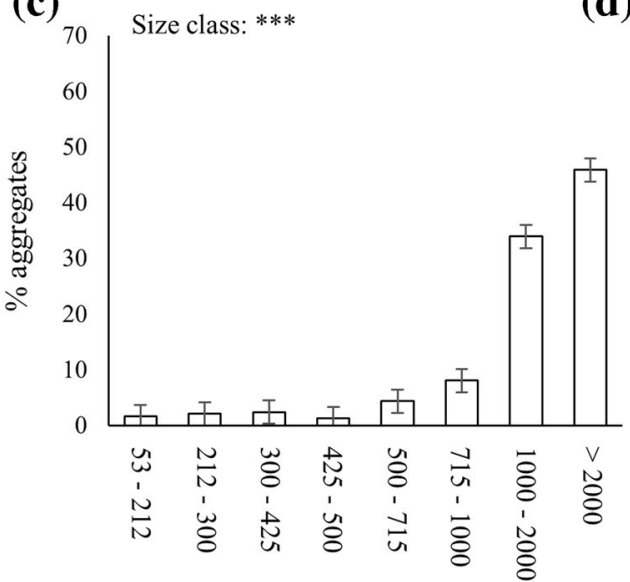

Aggregate size classes $(\mu \mathrm{m})$

Fig. 5 Soil aggregate size distribution showing the starting condition at Week $0(\mathbf{a}, \mathbf{c})$ and the effect of plants at Week $6(\mathbf{b}, \mathbf{d})$ for the sandy loam soil $(\mathbf{a}-\mathbf{b})$ and the clay soil $(\mathbf{c}-\mathbf{d})$. Bars denote

\section{Aggregate size distribution}

At Week 0 , the aggregate size distribution of the sandy loam showed an increasing proportion of aggregates in size class $53-500 \mu \mathrm{m}$, followed by a reverse of this trend for aggregates $>2000 \mu \mathrm{m}$ (Fig. 5a). This trend was interrupted at $425-500 \mu \mathrm{m}$, where this size class constituted a significantly smaller proportion than neighbouring classes (Fig. 5a). There was an extremely low proportion of aggregates $>2000 \mu \mathrm{m}$ (approximately $0.4 \%$, Fig. 5a). At Week 6, this pattern was still manifest, and there was no significant effect of plants $(P>0.05$; Fig. $5 b)$. For the clay soil, there was a general trend of an increase in proportion of aggregates with increasing size class, but a substantial increase for pores $>1000 \mu \mathrm{m}$, with the greatest proportion $>2000 \mu \mathrm{m}$ (Fig. $5 \mathrm{c})$. This pattern persisted at Week 6 , where there was a significant effect of plants with respect to aggregates

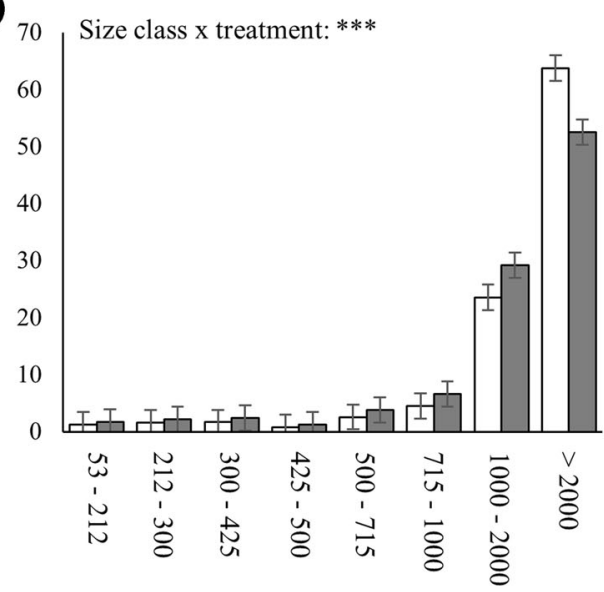

Aggregate size classes $(\mu \mathrm{m})$

means $(n=4)$ expressed as the percentage of aggregates relative to the total volume, whiskers denote pooled standard errors

$>1000 \mu \mathrm{m}$; planted soils had a significantly greater proportion of aggregates 1-2 mm than unplanted soils, but this pattern was reversed for aggregates $>2000 \mu \mathrm{m}$ $(P<0.05$; Fig. 5 d).

\section{Discussion}

Whilst the organic matter content was lower in the sandy soil, this is essentially inevitable for similarly-managed and co-located clay versus sandy arable soils, and the primary difference between the soils used in this study was textural. The nature of the aggregate size distribution was different between the textures: approximately $80 \%$ of all aggregates were $>1000 \mu \mathrm{m}$ for the clay, whereas in sandy loam soil the aggregate sizes were more evenly distributed throughout the sizes $<2000 \mu \mathrm{m}$ with $0.5 \%$ of aggregate sizes $>2000 \mu \mathrm{m}$ 
(Fig. 5). For the clay soil, the larger proportion of aggregates $>1000 \mu \mathrm{m}$ can be attributed to the greater proportion of clay particles due to their capacity to bound together (Tisdall and Oades 1982; Dexter 1988; Blake et al. 2003). The presence of plants did not impact the aggregate size distribution in the sandy loam soil. This may be due to a lack of any substantial wet:dry cycles imparted, which is known to stabilise aggregate (Bronick and Lal 2005) as the samples were held at a fixed water potential in this experiment. During wetting, water can disperse or swell clay particles which leads to increased contact between clay and other particles, and therefore binding during the drying phase (Singer et al. 1992). Furthermore, sandy loam soil contained a low proportion of clay $(9.5 \%)$, which is representative of a non-cohesive soil. Thus in non-cohesive soil, the binding due to the presence of clay is reduced leading to a reduction of the root action on the aggregation (Degens et al. 1994; Six et al. 2004). We wished to avoid such effects in this study in order to investigate the inherent effects of the plant on structural genesis. Hence in both soils, the water regime was constant during the experiment, thus the change in wet and dry cycles were not responsible for the greater proportion of aggregates $>2000 \mu \mathrm{m}$ observed in the unplanted treatment for the clay soil. Thus, the aggregation in the unplanted treatment might be due to other biotic factors, such as microbial activity. The planted soils showed a decrease in the percentage of aggregate sizes $>2000 \mu \mathrm{m}$ and an increase in the percentage of aggregate sizes 1000-2000 $\mu \mathrm{m}$ (Fig. 5 ). The greater proportion of aggregates sizes between 1000 and $2000 \mu \mathrm{m}$ in the planted soil might have resulted from fragmentation of bigger aggregates by root penetration or development via root action, and localised wet-dry cycles induced by the presence of plants (Materechera et al. 1994; Chan and Heenan 1996; Jin et al. 2013). However, the moisture content of the column was kept constant during the experiment via the use of a tension table, and the transpiration rates of plants was not measured. Such localised effects might have induced a rearrangement of the clay particles around the roots and modified the aggregate size distribution (Reid and Goss 1982; Six et al. 2004; Gregory et al. 2009). Therefore, in the more cohesive soil, roots appear to generate fragmented aggregates, which may facilitate water infiltration or drainage within the aggregates (Fig. 1e; Materechera et al. 1994). This in turn would have arguably positive effects upon water availability to the plants through the generation of a wider pore sizes from sizes between 0.05 and $0.16 \mathrm{~mm}$, which are associated to the transmission pores (Metzger and Yaron 1987; Watts and Dexter 1997).

For both soil textures, a decrease in porosity was observed in unplanted soil at Week 2 (from 14.9 to $8.9 \%$ for the sandy loam soil and from 10.4 to $8.2 \%$ for the clay soil) which maintained constant until Week 6 (Fig. 2) which is most likely a consequence of settling of the soil due to gravity. Moreover, the presence of cracks observed in both columns was attributed to the root action as the water content was controlled (Fig. 1). This observation corroborates with a recent study that showed cracks associated with root formation (Helliwell et al. 2019). However, soil texture profoundly influenced the soil structural development of planted soil: in sandy loam soil, porosity decreased constantly over the 6 weeks (from 15.4 to $7 \%$ ) whereas, in clay soil, the porosity stayed constant over the 6 weeks (approximately $7.8 \%$ ). For the sandy soil, the decrease of the porosity could have been induced by the rearrangement of soil particles which increased pores $<40 \mu \mathrm{m}$ and these pores were not included in the measured porosity. Furthermore, the results from the sandy loam soil was consistent with a previous study which observed, a decrease of porosity in rhizosphere soil induced by root growth of tomato plants for the same soil texture (Helliwell et al. 2017). However, the results for clay soils are divergent from Helliwell et al. (2017) who detected an increase of rhizosphere porosity in this case. The impact of plants on the bulk soil, here measured for pores $>40 \mu \mathrm{m}$ resolution, could be slower compared to the rhizosphere porosity, measured at $>12 \mu \mathrm{m}$ resolution (Helliwell et al. 2017). This observation was also observed at the field level: the presence of plants decreased the porosity of a sandy soil compared to the increase of the porosity for a clay soil (Bacq-Labreuil et al. 2018). Therefore, the indications are that a plant can modify soil structure differently depending on the soil texture. The results for the sandy loam soil was consistent with another study which showed plants growing at a bulk density of $1.2 \mathrm{~g} \mathrm{~cm}^{-3}$ decreased the soil porosity (Martin et al. 2012). However, these results are divergent from Feeney et al. (2006) for the soil of the same textural class, at a bulk density of $1.3 \mathrm{~g} \mathrm{~cm}^{-3}$, where the presence of plants and soil microbiota increased the porosity. Our results suggest that the initial configuration of the pore network, defined by soil texture and bulk density, affects subsequent root growth responses and the associated impacts of roots on soil structural genesis. 
The results obtained via X-ray $\mathrm{CT}$ imaging contrasted with those of the aggregate size distributions. In the sandy loam soil, there was no significant impact of the plants upon soil aggregation whereas plants significantly affected the pore network. In comparison, for the clay soil, there was a significant increase of aggregates $<1000 \mu \mathrm{m}$, while the plants induced a constant porosity. These observations show that the aggregate size distribution metrics concealed information regarding the in situ soil structure.

Neither soil texture showed a significant plant effect on pore size distribution or pore connectivity after 6 weeks growth. A longer experiment might have revealed a greater influence of plants on soil structural genesis. In the sandy loam soil, the presence of plants decreased the pore surface density, i.e. decreasing poresolid interfaces (Fig. $3 \mathrm{~g}$-i). This meant the presence of plants reduced the irregular shaped-pores or elongated pores within the pore network (Vogel et al. 2010; BacqLabreuil et al. 2018). In clay soil, the pore solid interface increased in the planted soils (Fig. 4 g-i), which suggests that elongated or irregular shaped-pores increased within the pore network. The formation of more irregularshaped pores would likely influence the microbial community due to the creation of new habitats and a wider range of niches (Holden 2011). A more diverse pore structure and heterogeneity in pore morphology can also affect soil hydrology, via modifying water flow at a local scale and the nature of water film continua. Therefore, the same plant genotype had two distinctive effects upon the modification of pore morphology depending on the inherent soil texture. Therefore, the prescription of crops for specific characteristics such as root morphology, rhizodeposition, might be better informed by consideration of the soil texture in which they are grown. Especially that the same plant species is affected differently depending on soil textures. This characteristic might be important for breeders and farmers in order to prescribe plant species that are optimal for the needs of the farmers and depending on the soil texture.

Therefore, farmers, depending on their requirements (such as water management, compaction, etc) could prescribe different plant species depending on their characteristics, but taking in account the soil texture. Sandy soils are usually free draining, thus there may be an adaptive advantage where roots reduce the porosity in soils in which they are growing, which will likely increase the retention of water. Therefore, cover crops could potentially be used to prime soil structure before sowing the main crop, specifically in sandy soil to enhance the retention of water, and in clay soils to increase water transmission. Further studies are required to understand whether different plant species affect such soil structural dynamics in different ways (Ehrmann and Ritz 2013; Erktan et al. 2018). We postulate this is likely given the diversity of root morphologies, rhizodeposition patterns and higher-order interactions between plants and soil biota. These observations also have implications from an ecological perspective, for example in the way vegetation may modulate soil structural dynamics during successional processes, which appears to have been barely considered.

\section{Conclusions}

This study revealed a contrasting effect of soil textural characteristics on soil structural genesis. The results confirmed our hypothesis that a plant can modify soil aggregate size distribution and pore networks differently depending on the inherent soil texture, manifest by different aggregate size distributions, and the contrasting effect of plants in both textural classes. However, the second hypothesis was not fully supported for both soils. For the sandy loam soil, the presence of roots decreased porosity, pore surface density, but had no significant impact on pore size distribution and pore connectivity after 6 weeks of growth. For the clay soil, the presence of roots maintained the porosity constant over the 6 weeks, but had no effect on the pore connectivity, contradicting the second hypothesis, but increased the pore surface density, which supported it. These results showed that impact of plants on soil pore architecture depends on textural characteristics.

Acknowledgements We thank Pr. Hu Zhou for his assistance with the software QuantIm, and Paul Brown for supplying seed of Phacelia. This work was performed at the University of Nottingham Hounsfield facility. The University of Nottingham Hounsfield Facility receives funding from BBSRC (Swindon, UK), and The Wolfson Foundation (London, UK). This work is supported by the BBSRC-funded Soil to Nutrition strategic programme (BBS/E/C/000I0310) and jointly by the Natural Environment Research Council and BBSRC as part of the Achieving Sustainable Agricultural Systems research programme (BBS/E/C/000I0130). We also thank the anonymous reviewers for their insight and suggestions for improvement. 
Open Access This article is distributed under the terms of the Creative Commons Attribution 4.0 International License (http:// creativecommons.org/licenses/by/4.0/), which permits unrestricted use, distribution, and reproduction in any medium, provided you give appropriate credit to the original author(s) and the source, provide a link to the Creative Commons license, and indicate if changes were made.

\section{References}

Abdollahi L, Munkholm LJ, Garbout A (2014) Tillage system and cover crop effects on soil quality: II. Pore characteristics. Soil Sci Soc Am J 78:271. https://doi.org/10.2136 /sssaj2013.07.0302

Bacq-Labreuil A, Crawford J, Mooney SJ, Neal AL, Akkari E, McAuliffe C, Zhang X, Redmile-Gordon M, Ritz K (2018) Effects of cropping systems upon the three-dimensional architecture of soil systems are modulated by texture. Geoderma 332:73-83. https://doi.org/10.1016/J. GEODERMA.2018.07.002

Blake JJ, Spink JH, Dyer C (2003) Factors affecting cereal establishment and its prediction. HGCA Res Rev 51:1-53

Bodner G, Leitner D, Kaul HP (2014) Coarse and fine root plants affect pore size distributions differently. Plant Soil 380:133151. https://doi.org/10.1007/s11104-014-2079-8

Bronick CJ, Lal R (2005) Soil structure and management: a review. Geoderma 124:3-22. https://doi.org/10.1016/j. geoderma.2004.03.005

Bullock P, Murphy CP (1983) Soil Micromorphology 2: Soil Genesis., Berkhamste

Burr-Hersey JE, Mooney SJ, Bengough AG, Mairhofer S, Ritz K (2017) Developmental morphology of cover crop species exhibit contrasting behaviour to changes in soil bulk density, revealed by X-ray computed tomography. PLoS One 12:118. https://doi.org/10.1371/journal.pone.0181872

Cercioglu M, Anderson SH, Udawatta RP, Haruna SI (2018) Effects of cover crop and biofuel crop management on computed tomography-measured pore parameters. Geoderma 319:80-88. https://doi.org/10.1016/j.geoderma.2018.01.005

Chan KY, Heenan DP (1996) The influence of crop rotation on soil structure and soil physical properties under conventional tillage. Soil Tillage Res 37:113-125. https://doi.org/10.1016 /0167-1987(96)01008-2

Chan KY, Heenan DP (1999) Microbial-induced soil aggregate stability under different crop rotations. Biol Fertil Soils 30: 29-32. https://doi.org/10.1007/s003740050583

Czarnes S, Hallett PD, Bengough a G, Young IM (2000) Root- and microbial-derived mucilages affect soil structure and water transport. Eur J Soil Sci 51:435-443. https://doi.org/10.1046 j.1365-2389.2000.00327.x

Degens BP, Sparling GP, Abbott KL (1994) The contribution from hyphae, roots and organic carbon constituents to the aggregation of a sandy loam under long-term clover-based and grass pastures. Eur J Soil Sci 45:459-468. https://doi. org/10.1111/j.1365-2389.1994.tb00531.x

Dexter AR (1988) Advances in characterization of soil structure. Soil Tillage Res 11:199-238
Duchene O, Vian JF, Celette F (2017) Intercropping with legume for agroecological cropping systems: complementarity and facilitation processes and the importance of soil microorganisms. A review. Agric Ecosyst Environ 240:148-161. https://doi.org/10.1016/j.agee.2017.02.019

Ehrmann J, Ritz K (2013) Plant: soil interactions in temperate multi-cropping production systems. Plant Soil 376:01-29. https://doi.org/10.1007/s11104-013-1921-8

Erktan A, McCormack ML, Roumet C (2018) Frontiers in root ecology: recent advances and future challenges. Plant Soil 424:1-9. https://doi.org/10.1007/s11104-018-3618-5

Feeney DS, Crawford JW, Daniell T, Hallett PD, Nunan N, Ritz K, Rivers M, Young IM (2006) Three-dimensional microorganization of the soil-root-microbe system. Microb Ecol 52:151-158. https://doi.org/10.1007/s00248-006-90628

Fernandez AL, Sheaffer CC, Wyse DL, Staley C, Gould TJ, Sadowsky MJ (2016) Structure of bacterial communities in soil following cover crop and organic fertilizer incorporation. Appl Microbiol Biotechnol 100:9331-9341. https://doi. org/10.1007/s00253-016-7736-9

Finney DM, Buyer JS, Kaye JP (2017) Living cover crops have immediate impacts on soil microbial community structure and function. J Soil Water Conserv 72:361-373. https://doi. org/10.2489/jswc.72.4.361

Gould IJ, Quinton JN, Weigelt A, de Deyn GB, Bardgett RD (2016) Plant diversity and root traits benefit physical properties key to soil function in grasslands. Ecol Lett 19:11401149. https://doi.org/10.1111/ele.12652

Gregory AS, Watts CW, Griffiths BS, Hallett PD, Kuan HL, Whitmore AP (2009) The effect of long-term soil management on the physical and biological resilience of a range of arable and grassland soils in England. Geoderma 153:172185. https://doi.org/10.1016/j.geoderma.2009.08.002

Hacke UG, Sperry JS, Ewers BE, Ellsworth DS, Schäfer KVR, Oren R (2000) Influence of soil porosity on water use in Pinus taeda. Oecologia 124:495-505

Haynes RJ, Beare MH (1997) Influence of six crop species on aggregate stability and some labile organic matter fractions. Soil Biol Biochem 29:1647-1653. https://doi.org/10.1016 /S0038-0717(97)00078-3

Helliwell JR, Sturrock CJ, Mairhofer S, Craigon J, Ashton RW, Miller AJ, Whalley WR, Mooney SJ (2017) The emergent rhizosphere: imaging the development of the porous architecture at the root-soil interface. Sci Rep 7:14875. https://doi. org/10.1038/s41598-017-14904-w

Helliwell JR, Sturrock CJ, Miller AJ, Whalley WR, Mooney SJ (2019) The role of plant species and soil condition in the physical development of the rhizosphere. Plant Cell Environ. https://doi.org/10.1111/pce.13529

Holden PA (2011) How do the microhabitats framed by soil structure impact soil bacteria and the processes that they regulate? Eds K Ritz I Young Archit Biol Soils Life Inn Sp Chapter 7:118-148

Jackson RB, Sperry JS, Dawson TE (2000) Root water uptake and transport : using physiological predictions. Trends Plant Sci 5:482-488

Jin K, Shen J, Ashton RW, Dodd IC, Parry MAJ, Whalley WR (2013) How do roots elongate in a structured soil? J Exp Bot 64:4761-4777. https://doi.org/10.1093/jxb/ert286 
Kézdi A (1974) Handbook of soil mechanics. Soil Physics, vol 1, Elsevier S

Li Y, Xu H, Cohen S (2005) Long-term hydraulic acclimation to soil texture and radiation load in cotton. Plant Cell Environ 28:492-499. https://doi.org/10.1111/j.1365 3040.2005.01291.x

Martin SL, Mooney SJ, Dickinson MJ, West HM (2012) Soil structural responses to alterations in soil microbiota induced by the dilution method and mycorrhizal fungal inoculation. Pedobiologia (Jena) 55:271-281. https://doi.org/10.1016/j. pedobi.2012.06.001

Materechera SA, Kirby JM, Alston AM, Dexter AR (1994) Modification of soil aggregation by watering regime and roots growing through beds of large aggregates. Plant Soil 160:57-66

Metzger L, Yaron B (1987) Influence of sludge organic matter on soil physical properties. In: Stewart BA (ed) Advances in Soil Science Vol 7. Springer-Verlag, New York Inc., pp 141-163

Patkowska E, Konopiński M (2013) The role of oat, common vetch and tansy phacelia as cover plants in the formation of microorganisms communities in the soil under the cultivation of root chicory (cichorium intybus var. sativum bisch.) and salsify (tragopogon porrifolius var. sativus (gat. Acta Sci Pol, Hortorum cultus 12:179-191

Rabot E, Wiesmeier M, Schlüter S, Vogel HJ (2018) Soil structure as an indicator of soil functions: a review. Geoderma 314 : 122-137. https://doi.org/10.1016/j.geoderma.2017.11.009

Reicosky DC, Forcella F (1998) Cover crop and soil quality interactions in agroecosystems. J Soil Water Conserv 53: 224-229

Reid JB, Goss MJ (1982) Interactions between soil drying due to plant water-use and decreases in aggregate stability caused by maize roots. J Soil Sci 33:47-53. https://doi.org/10.1111 /j.1365-2389.1982.tb01746.x

Rillig MC, Wright SF, Eviner VT (2002) The role of arbuscular mycorrhizal fungi and glomalin on soil aggregation comparing the effects of five plant species. Plant Soil 238:325-333

Ritz K, Young IM (2011) Architecture and biology of soils. CABI, Wall

Saxton KE, Rawls WJ, Romberger JS, Papendick RI (1986) Estimating generalized soil-water characteristics from texture. Soil Sci Soc Am J 50:1031-1036

Schlüter S, Großmann C, Diel J, Wu GM, Tischer S, Deubel A, Rücknagel J (2018) Long-term effects of conventional and reduced tillage on soil structure, soil ecological and soil hydraulic properties. Geoderma 332:10-19. https://doi. org/10.1016/j.geoderma.2018.07.001

Schneider CA, Rasband WS, Eliceiri KW (2012) NIH image to ImageJ: 25 years of image analysis. Nat Methods 9:671-675

Scott DA, Baer SG, Blair JM (2017) Recovery and relative influence of root, microbial, and structural properties of soil on physically sequestered carbon stocks in restored grassland. Soil Sci Soc Am J 81:50. https://doi.org/10.2136 /sssaj2016.05.0158

Singer MJ, Southard RJ, Warrington DN, Janitzky P (1992) Stability of synthetic sand-clay aggregates after wetting and drying cycles. Soil Sci Soc Am J 56:1843. https://doi. org/10.2136/sssaj1992.03615995005600060032x

Six J, Bossuyt H, Degryze S, Denef K (2004) A history of research on the link between (micro) aggregates, soil biota, and soil organic matter dynamics. Soil Tillage Res 79:7-31. https://doi.org/10.1016/j.still.2004.03.008

Six J, Frey SD, Thiet RK, Batten KM (2006) Bacterial and fungal contributions to carbon sequestration in agroecosystems. Soil Sci Soc Am J 70:555. https://doi.org/10.2136 /sssaj2004.0347

Storr T, Simmons RW, Hannam JA (2019) A UK survey of the use and management of cover crops. Ann Appl Biol aab12488. https://doi.org/10.1111/aab.12488

Tisdall JM, Oades JM (1982) Organic matter and water-stable aggregates in soils. J Soil Sci 33:141-165

van Breemen N (1993) Soils as biotic constructs favoring net primary productivity. Geoderma 57:183-211. https://doi. org/10.1016/0016-7061(93)90002-3

Vogel HJ, Weller U, Schlüter S (2010) Quantification of soil structure based on Minkowski functions. Comput Geosci 36:1236-1245. https://doi.org/10.1016/j.cageo.2010.03.007

Watts CW, Dexter AR (1997) The influence of organic matter in reducing the destabilization of soil by simulated tillage. Soil Tillage Res 42:253-275. https://doi.org/10.1016/S01671987(97)00009-3

Zhou H, Fang H, Mooney SJ, Peng X (2016) Effects of long-term inorganic and organic fertilizations on the soil micro and macro structures of rice paddies. Geoderma 266:66-74. https://doi.org/10.1016/j.geoderma.2015.12.007

Publisher's note Springer Nature remains neutral with regard to jurisdictional claims in published maps and institutional affiliations. 